\title{
Reflexões Temáticas sobre Eqüidade e Saúde: o caso do SUS
}

\section{Refletions about Health Equity: the case of Unified Health System of Brazil}

Gastão Wagner de Sousa Campos

Professor livre docente do Departamento de Medicina Preventi-

va e Social da FCM/UNICAMP.

E-mail: gastaowagnerळmpc.com.br

\section{Resumo}

Foi realizada uma análise do conceito de eqüidade, bem como sobre as implicações práticas de suas várias acepções. Foram encontrados dois principais sentidos para o conceito de eqüidade: um genérico e equivalente ao de justiça e igualdade; e o segundo, mais específico, pelo qual eqüidade se refere à capacidade de estabelecer julgamento e tratamento conforme a singularidade de cada situação. Realizou-se uma revisão de estudos sobre eqüidade e saúde, encontrandose que o primeiro sentido tem predominado ao se relacionar eqüidade e políticas sociais. Avaliações realizadas sobre a eqüidade no SUS, na última década, encontraram elementos de avanço e áreas em que persistem desigualdades de acesso, financiamento e utilização de serviços.

Palavras-chave: Eqüidade; Sistema de saúde; Políticas sociais. 


\section{Abstract}

A conceptual analysis of equity and pragmatic implications of their several notions was made. Two main meanings were found: a general one, when the sense of equity is very similar to justice and equality; and a second related to the notion of singular situation and to difference between subjects. It was found that on the health area the first meaning is more used. A revision about equity evaluation during the last decade concerned with the Unique Health System (SUS) was undertaken. Positive results were found on services' access and utilization, but areas with iniquities persist. Key words: Equity; Health Systems; Social Policies.

\section{Considerações Conceituais sobre a Eqüidade}

Para uma filosofia da prática os conceitos não são inócuos. Refletem um compromisso de quem os inventa ou os emprega com certo entendimento do mundo ou com um determinado conjunto de valores. Os conceitos, portanto, têm valor de uso; ou seja, são úteis para a gestão da vida. A construção de um logos ou de uma racionalidade implica na invenção de uma rede sistêmica de conceitos, sempre. Alguns autores contemporâneos chegam a afirmar que toda e qualquer filosofia é uma rede de conceitos e que o filosofar seria construir, reconstruir e desconstruir conceitos (Deleuze e Guattari; 1992). Isso não ocorre apenas na constituição da racionalidade filosófica, passa-se, também, tanto na constituição do discurso científico, quanto na do político, moral ou religioso. Isso acontece ainda quando algum conceito remete seus aplicadores a um outro mundo. Seria o caso de “alma eterna”, independentemente do debate sobre a veracidade da existência ou não de um ser perene acoplado a cada humano; sem dúvida, essa concepção teve e tem uma capacidade de interferir sobre o sentido e o significado da existência de bilhões de pessoas. Em decorrência, "alma eterna" é um conceito operante, independentemente de sua veracidade ou adequação epistêmica a tal ou qual corrente de pensamento.

Dentro dessa perspectiva, um conceito - eqüidade, no caso - deveria ser analisado tanto em si mesmo, em sua constituição ontológica, quanto em virtude de suas relações sistêmicas com outros conceitos em um determinado contexto particular - no caso, eqüidade e políticas sociais e SUS.

O conceito de eqüidade tem sido utilizado em dois sentidos, um geral e outro específico. No sentido mais vago o termo se confunde com o próprio significado da palavra justiça. Os termos se equivaleriam, seriam sinônimos, e indicariam a preocupação em se estabelecer regras justas para a organização social. Aequale em latim era o termo utilizado para designar iguais; a palavra eqüidade tem essa mesma raiz etimológica. Portanto, eqüidade nessa acepção mais geral também se refere à igualdade (Comte-Sponville; 2003).

Em saúde tem predominado a utilização do conceito eqüidade dentro desse sentido genérico (Starfield, 2001; Almeida, 2002). 
No entanto, vários pensadores atribuem um outro significado mais específico a esse conceito. Para Aristóteles, a eqüidade era uma virtude que permitiria adequar a generalidade das leis a situações concretas. Serviria como que uma espécie de corretivo da lei (Aristóteles 384-322 A.C.; 2004). Corresponderia à justiça aplicada no cotidiano pelos seres humanos reais, seria aquela racionalidade que permitiria adaptar um conhecimento ou um julgamento elaborado com base na tradição, ou em leis impessoais ou em outras experiências a uma situação diferente de todas aquelas previstas. A eqüidade seria o exercício vivo da justiça; para ele, a única forma de contar-se com uma justiça realmente justa.

Norberto Bobbio também valoriza a importância de realizar-se uma adequação das normas genéricas a cada contexto específico. Para ele: "Eqüidade é a adaptação de uma norma ao caso singular, que não permite uma perfeita equiparação aos casos previstos" (Bobbio; 2000 - p: 311). Para esse pensador, portanto, as normas, por sua origem genérica e por se referirem aos universais (conhecimentos ou valores), produziriam, com freqüência, injustiça quando aplicadas literalmente aos casos específicos. A aplicação de normas genéricas exigiria a prudência e um julgamento específico de sua justeza em cada situação singular. Nesse sentido, o autor comenta que a "desigualdade de tratamento corresponde a um reconhecimento da desigualdade de situação" (Bobbio, 2000 - p: 312). No fundo, a eqüidade tomada nessa acepção obriga a deduzir-se que a construção da justiça e da igualdade implica no reconhecimento das diferenças e no tratamento dessas diferenças de forma distinta, ainda que sempre guardando uma referência às normas genéricas.

Nesse entendimento, o conceito de eqüidade tem uma forte dependência de outros conceitos ou valores - no caso, a universalidade do conhecimento ou da lei, a integralidade de ofertas possíveis - e guarda uma relação estreita com a subestimada e sempre adiada diretriz comunista de "a cada um segundo sua necessidade”. O pensamento marxista previa que, com o progresso social, o critério de justiça passaria da consigna de "a cada um segundo seu trabalho" para aquela outra acima citada, mais sofisticada e com maior sensibilidade que indicaria uma futura possibilidade de se organizar uma máquina social que distribuísse bens e serviços conforme a necessidade de cada pessoa (Marx \& Engels - 1848; 200o).

O sentido forte de eqüidade é exatamente esse - a cada um segundo sua necessidade - e vem sendo considerado um modo utópico para gerir a vida, particularmente depois da falência global das experiências que se classificavam comunistas. Essa possibilidade passou a ser vista como alguma coisa a ser considerada somente em algum futuro paraíso terrestre. A prática desse conceito seria sempre algo para o futuro, um pouco como a distribuição de renda, sempre haveria argumentos racionais que justificariam o seu adiamento.

Na realidade, a operacionalização desse conceito exige tal grau de sofisticação e de delicadeza da política, da gestão e da própria organização social que em poucas situações concretas foi possível observar-se sua aplicação efetiva. Em geral, as variações na aplicação de normas sociais, morais ou científicas têm ocorrido muito mais em função de atores sociais que acumulam poder do que de outros com carências. A prática da eqüidade dependeria de um elevado grau de democracia, de distribuição das cotas de poder, do controle social do exercício desse poder descentralizado de maneira a se evitar abusos e, paradoxalmente, também de um elevado grau de autonomia dos agentes sociais que praticam os julgamentos e instituem os tratamentos, sem o que não poderiam operar conforme cada situação singular.

Observa-se, então, que nessa segunda acepção o conceito de eqüidade funciona em sistema de dependência com aqueles conceitos que dizem respeito à singularidade da existência humana. Assim, ele influencia e é influenciado pela concepção que reconhece cada pessoa como um cidadão de direitos, ou ainda mais fortemente pela que identifica em cada pessoa um sujeito com grau relativo de liberdade e de autonomia. Há uma correspondência de orientação entre essa segunda concepção de eqüidade e as noções de situação ou de conjuntura específicas caras à fenomenologia e a outras correntes de pensamento. 0 manejo da eqüidade nesta acepção implica, pois, na convivência com a noção de sujeito e no reconhecimento da variedade das situações existenciais e históricas. As pessoas e os fatos não seriam julgados apenas em si mesmos, mas também em função do modo como foram produzidos. Poder-se-ia identificar atenuantes ou agravantes no julgamento conforme os antecedentes 
envolvidos. Atenas não deveria julgar igualmente como inimigos dois povos que se uniram para atacála, caso um deles tivesse sido obrigado a isso por estar dominado pelo outro atacante mais forte e que o conquistara previamente; esse é um exemplo da aplicação desse critério de eqüidade à política citado por antigos filósofos.

Esta dependência do modo como são produzidos os fenômenos complica bastante a definição de critérios avaliativos de eqüidade. Uma política social seria eqüitativa quando atendesse a que critérios? Essa não é uma pergunta auto-evidente, conforme imaginam alguns analistas. $O$ eqüitativo deveria atender necessidades coletivas, e, portanto, genéricas, ou a necessidades singulares, relativas a alguns sujeitos mais vulneráveis do que outros? Fez escola a concepção de que a busca da igualdade se conseguiria com medidas coletivas e a defesa da autonomia e liberdade com leis dirigidas ao indivíduo. Ora, se tomarmos a noção de eqüidade em seu duplo sentido, no sentido tradicional como igualdade, e na versão aristotélica que remete ao julgamento valorativo dos contextos singulares, embaralha-se esse suposto ordenamento, já que a construção da eqüidade dependeria tanto de leis e de políticas voltadas para o coletivo, quanto da instituição de mecanismos singulares que permitisse regular e até mesmo alterar a aplicação dessas diretrizes coletivas aos casos particulares ou individuais.

Quanto às necessidades, haveria de se refletir sobre o modo como foram construídas. Que forças sociais e que interesses influenciaram em sua constituição como necessidades sociais? No caso da saúde, teriam a medicina e a clínica o monopólio para definir os critérios de julgamento daquilo que é ou não prioritário? Ou, conforme o previsto na Lei 8080 (Brasil -b; 1990), a epidemiologia poderia com base em indicadores de morbidade e mortalidade e em cálculos estatísticos definir prioridades na alocação de recursos? O que seria mais eqüitativo, um plano habitacional ou assegurar tratamento para AIDS e câncer para uma população de uma grande favela? Qual o papel político dos supostos beneficiários na eleição de prioridades e na definição de critérios distributivos de bens ou serviços? A eqüidade se mediria pelas necessidades humanas de cada pessoa ou pelo seu mérito: a cada um de acordo com seu mérito ou de acordo com sua vulnerabilidade ou risco?
A resposta a todas essas perguntas depende da utilização combinada de outros critérios além do de eqüidade. Se a noção de eqüidade vem ligada à de direito universal, teremos um sentido para as respostas. Se essa noção de direito automático à saúde, educação e a outras políticas de proteção social não é aceita, os critérios para avaliar a eqüidade serão outros. Nesse sentido, é importante reconstituir a rede de relações na qual estaria inscrito o termo eqüidade. 0 sentido e o significado do termo eqüidade se modificam conforme o sistema de valores, a concepção de organização social e mesmo de desenvolvimento econômico e social a que cada discurso se refere. Assim, a resposta à pergunta central desse debate - o SUS estaria ou não produzindo eqüidade? - precisaria ser mais bem contextualizada; ou seja, é necessário sempre explicitar a que aspectos da eqüidade o sistema estaria ou não atendendo. Com certeza, estará contemplando alguns aspectos melhor que outros, e ignorando algumas dimensões desse conceito em função de sua organização segundo interesses e segundo a correlação de forças interessadas em impedir esse ou aquele tipo de redistribuição de recursos.

Essa concepção da eqüidade como um julgamento e uma intervenção situacional, ou seja, em acordo com a singularidade de cada caso, baseia-se no pressuposto de que não há estrutura, ou normas, ou sistema de leis ou de conhecimento perfeitos. Não que fossem equivalentes todos, não. Há critérios que permitem avaliar a potência de eqüidade, ou seja, a capacidade potencial para reconhecer diferenças e para proteger os mais fracos, os mais vulneráveis, contida em uma estrutura genérica ou em um conjunto de leis ou de programas, isto é, naquilo que foi institucionalizado (Drachler; Côrtes; Castro et al; 2003).

No entanto, o que essa noção nos obriga é a reconhecer que nenhum sistema teria uma capacidade absoluta e ubíqua de, ao definir regras e valores gerais, contemplar a imensa variedade das situações singulares.E que haveria ainda necessidade sempre de um espaço de autonomia para que os operadores desses sistemas, em interação com os usuários, atenuassem ou até mesmo modificassem o previsto nas determinações genéricas. Seria como que um reconhecimento da necessidade de constituírem-se instituições mutantes, já que o exercício cotidiano e sistemático da busca de eqüidade constituiria um acúmulo 
empírico de evidências sobre falhas existentes na norma geral e também forneceria indicações de novos ordenamentos que permitissem um aperfeiçoamento dessas normas.

Uma outra forma de institucionalizar regras coletivas sem impedir esse exercício da eqüidade em situações distintas é buscar, ao mesmo tempo, tanto a composição de regras genéricas, quanto a preservação de certo grau de autonomia de julgamento e de ação para os operadores locais.

$\mathrm{Na}$ área da saúde, alguns autores, particularmente a partir da década de 1990 do século XX, abraçaram essa perspectiva ativa e, quem sabe, poder-se-ia dizer construtivista da eqüidade em saúde. Em realidade, procuraram apontar que a justiça social não adviria somente da disponibilidade de bens ou serviços, mas também da oportunidade de aceder-lhes e ainda da capacidade dos protagonistas de defenderem sua própria vida.

Witehead (1992) escreveu sobre eqüidade enfatizando sua dependência do desenvolvimento potencial das pessoas e da sociedade, objetivando eliminar desvantagens e diferenças negativas, criando-se assim justa oportunidade de acesso aos serviços. 0 que diferenciaria essa visão da concepção liberal tradicional de igualdade baseada na igualdade de oportunidade? Talvez, ao se tomar como função das políticas de proteção social a eliminação dessas desvantagens, estar-se-ia aproximando essa visão de eqüidade daquela primeira, que pensa a igualdade assegurada pela justa organização da sociedade, inclusive, mediante políticas de defesa ativa dos vulneráveis. Apesar de vários países capitalistas, o Brasil entre eles, haverem adotado políticas sociais compensatórias ou de redistribuição de renda, não se poderia equivaler essa concepção àquela do liberalismo puro.

No entanto, outros autores (Scorel; 2001), (Lucchese; 2003) e (Siqueira-Batista e Schramm; 2005) apoiaram-se em Amartya Sen e em seu conceito de igualdade complexa para tentar trazer para a saúde conceitos que permitissem escapar a essa tradicional dicotomia entre pensar a igualdade e a justiça como produto ora de uma ordem social genérica, ora da livre-iniciativa de indivíduos isolados e descontextualizados. Esse pensador indiano sugere a utilização dos conceitos de capacidade e de funcionamento para pensar a superação das iniqüidades a partir do esforço e da iniciativa também dos atingidos pela iniqüidade, uma perspectiva ativa de intervenção a partir também dos injustiçados. Lucchese, em uma adaptação criativa, toma as noções de capacidade e de funcionamento para analisar a gestão pública de saúde no Brasil. Avalia a capacidade de governo dos entes federados subnacionais em decorrência da descentralização prevista na legislação sanitária brasileira. Ela conclui que essa maior governabilidade adquirida pelos estados e municípios vem ampliando o direito à saúde no Brasil, ainda que persistam importantes desigualdades regionais no tocante ao aceso e à qualidade dos serviços de saúde, às condições de vida das populações e ainda à distribuição espacial de recursos humanos (Lucchese; 2003).

Nesse mesmo período desenvolvi uma linha de pesquisa que buscava estratégias metodológicas voltadas para ampliar a capacidade de análise e de intervenção de indivíduos, grupos e organizações nos processos de saúde e doença. O conceito de capacidade dos sujeitos individuais ou coletivos foi desdobrado em capacidade de compreensão ou de interpretação de si mesmo e do contexto e em capacidade de agir sobre si mesmo e sobre esse contexto. O apoio paidéia foi a metodologia construída para sustentar e estimular essa ampliação da capacidade de análise e de intervenção de sujeitos individuais ou coletivos, como a família, equipe, movimento social, organização de representação, empresa pública ou privada, objetivando a defesa do interesse próprio e da coletividade. 0 método do apoio paidéia busca ampliar a capacidade de esses sujeitos estabelecerem compromissos e contratos entre seus interesses singulares, os interesses de outros e a racionalidade das estruturas coletivas (leis, normas e valores) (Campos, 200o).

Para todos esses autores, a eqüidade depende bastante da capacidade da sociedade civil e de seus vários agrupamentos de interagirem com o estado, com os governos e com outros poderes institucionais, para construírem contextos favoráveis à justiça e à democracia.

Na realidade não se trataria de pensar uma oposição absoluta entre sistemas genéricos de leis, de valores ou mesmo sociais, e a possibilidade de haver variação singular em seu funcionamento cotidiano. Tampouco haveria oposição absoluta entre estruturas que busquem assegurar direito e justiça e outras voltadas para a ampliação da capacidade das pessoas de 
fazerem sua própria defesa. Tratar-se-ia de compatibilizar essas duas perspectivas, uma com origem em escolas que valorizam o coletivo, como o foi o marxismo, e outra em correntes de corte liberal, que enfatizam a responsabilidade do indivíduo sobre seu destino. Uma das marcas positivas dos países de socialismo real foi ofertar redes, mais ou menos amplas, de serviços voltados para a proteção às pessoas. 0 negativo foi que, simultaneamente, produziu-se um funcionamento social fechado e antidemocrático, que reduzia a possibilidade e a capacidade de intervenção dessas mesmas pessoas. Com isso, a sociedade civil, em todos esses países, demonstrou-se incapaz de controlar abusos de poder e, em grande medida, compactuou com a degeneração burocrática dos serviços públicos.

Essa concepção integradora depende de reconhecer-se a importância de um esforço sistemático para o aperfeiçoamento permanente das pessoas e instituições, uma espécie de atualização da velha consigna grega denominada Paidéia. Alberto Pellegrini, em estudo recente, defende a tese “(...) de que a informação e o conhecimento são bens públicos essenciais e que as iniqüidades de acesso a esses bens são importantes determinantes das iniqüidades em saúde”. Para permitir essa socialização do saber ele recomenda fortalecimento do processo democrático, multiplicação dos atores envolvidos com a elaboração e gestão das políticas de saúde, bem como ampliação dos espaços e oportunidades de interação entre os sujeitos envolvidos com saúde, no caso, pesquisadores, profissionais e usuários (Pellegrini; 2004). Trata-se de uma análise relevante e que chama atenção para o fato de que a construção da eqüidade depende de processos políticos e não apenas de controle avaliativo de recorte tecnocrático; ou seja, é necessário cuidar da eqüidade não somente mediante avaliações ex post, mas também mediante intervenções a priori dos agentes sociais; e de que esses agentes sociais necessitam de processos amplos de educação, de informação e de interação para que logrem capacitar-se para o exercício dessa espécie de regulação social - muito delicada para ficar a cargo somente dos políticos profissionais ou de especialistas tendentes a reproduzir lógicas corporativas.

No entanto, depois do debacle do socialismo real e da crise de legitimidade dos estados de bem-estar social, talvez fosse importante, sem renunciar a essa busca de reformas que tornem as estruturas e políti- cas mais justas, pensarse também no modo como esses sistemas poderiam permitir uma variação singular em seu funcionamento cotidiano. Exceção à regra não em função de interesses privados, mas de necessidades específicas de coletivos ou de pessoas mais vulneráveis a este ou àquele risco. Essa concepção depende da conquista de um importante grau de autonomia para os sujeitos, sejam eles operadores dos sistemas ou usuários dependentes.

No entanto, a autonomia, para que não se produza o caos ou uma competição selvagem, exige a contrapartida da auto-responsabilidade e do controle social. Nesse sentido, a eqüidade diz respeito ao denominado efeito Paidéia, ou seja, à constituição de um esforço sistemático para educar os sujeitos para um importante grau de autogoverno ou, melhor dizendo, de co-gestão dos sistemas e da vida como um todo. As pessoas não desenvolvem naturalmente capacidades de julgamento e de ação prática que assegurem justiça e eqüidade. Esse conhecimento e essa habilidade teriam de ser desenvolvidos, e o desenvolvimento dessa virtude jamais se daria fora de seu próprio exercício prático.

Além disso, a busca da eqüidade depende também de contextos democráticos, em que o poder de um é contraposto ao poder de outros. O exercício responsável e solidário da autonomia, ou seja, da capacidade de governo descentralizado, depende sempre de uma postura interna, de uma assunção pelo sujeito de valores e condutas que incluem o respeito ao outro e à coletividade, mas seria ingênuo atribuir apenas a cada pessoa o controle de sua própria autonomia. Tenderiam a multiplicarem-se os abusos; para evitar isso, é importante o controle externo, tanto proveniente do respeito a normas genéricas e aos contratos coletivos, quanto daquele exercido por outros pares em relação horizontal e também imbuídos de certo grau de autonomia e, portanto, de autogoverno.

Portanto, esse espaço de autonomia indispensável para o julgamento singular de situações não poderia ser exercido de modo unilateral. A co-gestão seria um modo de funcionamento fundamental, tanto para o exercício da política, como da gestão de organizações e até mesmo para se lidar com as práticas cotidianas da vida. Não bastaria, portanto, classificar a priori a prioridade ou a essencialidade desses ou daqueles tipos de necessidades, segundo critérios técnicos, 
políticos ou morais. Seria importante manter a possibilidade de eleição de prioridades mesmo em ato, ou seja, quando a vida mesma se realiza em sua inteireza.

Este é o aspecto utópico da eqüidade, já que remete à constituição de uma grande maioria de pessoas propensas a respeitar-se e a respeitar o direito dos outros, evitando, ao máximo, o uso da violência. A identificação da eqüidade com noções genéricas de justiça ou de direito facilita sua compreensão, mas não necessariamente facilita sua aplicação social.

Observa-se que esse dilema é comum à clínica e à Saúde Coletiva. Trata-se do paradoxo existente entre o conhecimento sobre o processo saúde e doença e o tratamento específico desses problemas. 0 conhecimento obrigatoriamente se constrói como uma ontologia, como seres processuais genéricos. Já a sua aplicação em casos concretos - problemas coletivos ou individuais de saúde - exige de cada operador uma capacidade criativa para, valendo-se desse conhecimento genérico, encontrar a justa medida para a variabilidade infinita dos problemas de saúde encarnados em contextos e em pessoas singulares. O velho dilema entre o genérico abstrato - a doença e a epidemia e os meios de intervenção considerados adequados - e o singular concreto, quando, em grande medida, cada caso é um caso específico e distinto dos demais, exigindo capacidade de improvisação e de criação.

\section{Equiidade e Política Social: o caso do SUS}

O Sistema Único de Saúde filia-se à tradição das políticas públicas, e nesse sentido foi concebido como um sistema de proteção social. Uma rede de serviços e um conjunto de normas destinados não apenas aos pobres, mas ao conjunto da sociedade, já que objetivava protegê-la de agravos sanitários e garantir fatores de proteção a todos os cidadãos.

É interessante observar-se que tanto na Constituição Federal, Título VIII - da ordem social, seção II, da Saúde de 1988, quanto na Lei Federal 8o8o de 19 de setembro de 1990, não há referência explícita ao termo eqüidade.

O artigo 196 da Constituição define: "Saúde é direito de todos e dever do Estado, garantido mediante políticas sociais e econômicas que visem à redução do risco de doença e de outros agravos e ao acesso universal e igualitário às ações e serviços para sua promoção, proteção e recuperação" (Brasil - a; 1988).

0 termo eqüidade aparece tão somente como um dos objetivos da Seguridade Social e referindo-se à justiça tributária no momento da constituição dos fundos de arrecadação financeira - "eqüidade na participação do custeio".

Os conceitos que aparecem em destaque na constituição do SUS são o de acesso universal e igualitário às ações e serviços de saúde. Ressalta-se que a saúde é considerada um direito universal e, ao mesmo tempo, um dever do Estado, que deveria assegurá-la não somente mediante ações específicas do setor saúde, mas também por meio de políticas sociais e econômicas que produzissem bem-estar.

Ora, essa perspectiva é oposta à que vinha se desenvolvendo em organismos financeiros internacionais e mesmo entre grande parte da intelectualidade nativa a partir dos anos 8 o do século XX. Em estudo sobre políticas de bem-estar e de proteção social no Brasil e na América Latina, Pochmann demonstra que “(...) o pequeno aparato social construído a partir da década de trinta passou a ser fortemente questionado desde a crise dos anos oitenta” (Pochmann; 2004).

Essa corrente de pensamento constituiu um ideário político e cultural que ganhou grande expressão no final do século XX, contrapondo-se ao colapso do socialismo real e à crise das políticas públicas em países capitalistas que as haviam adotado. Denominado de "ajuste econômico" ou "neoliberalismo", esse discurso, entre outros aspectos, passou a esgrimir contra aquela concepção de política pública expressa na criação do SUS, por exemplo. Desqualificava a pretensão de universalidade e de integralidade, quer em seu mérito - não haveria sentido garantir serviços a grupos que poderiam pagá-lo - quer por sua suposta inviabilidade econômica. Seriam sistemas muito caros, que drenariam recursos importantes para o financiamento da área produtiva e da infra-estrutura necessária ao desenvolvimento. Em contrapartida, recomendavam programas focais, dirigidos aos segmentos pobres (Almeida; 2002).

Foi nesse contexto que o termo eqüidade ganhou visibilidade política na América Latina. Na realidade, essa corrente fez uma apropriação do conceito, reduzindo sua abrangência e tratando de utilizá-lo apenas no sentido que lhes interessava, no caso, difundiram 
um pensamento que reduzia eqüidade à diminuição da pobreza.

Nessa perspectiva é que se passou a bombardear o SUS com a urgência de realizarem-se avaliações sistemáticas, voltadas centralmente para verificar se o sistema era progressivo ou regressivo, ou se o sistema contribuía de forma decisiva para a redistribuição de renda. Para essa concepção, as diretrizes da universalidade ou da integralidade do sistema seriam essencialmente equivocadas, conservadoras e, portanto, iníquas, já que destinavam importantes recursos do Estado e da sociedade para pessoas que não estavam incluídas nas faixas de pobreza absoluta ou relativa. Alguns documentos chegaram a criticar os programas de AIDS e de Saúde Mental brasileiros por assistirem todas as classes sociais, ou seja, por utilizar um critério de inclusão com base em outras categorias que não apenas a de pobreza (Rizzoto; 2001).

Na realidade, os sistemas públicos de saúde operam com outras categorias classificatórias de prioridade para a atenção. No caso, opera-se com os conceitos de risco ou de vulnerabilidade, que inclui o social, ou econômico, mas se acrescentam riscos subjetivos e biológicos. Todas as pessoas com a infecção pelo vírus da AIDS ou com câncer seriam prioritárias em relação a outros cidadãos considerados sadios. Entre eles, contudo, os com baixa vitalidade subjetiva ou com carências culturais, econômicas, habitacionais etc. deveriam ser atendidos com projetos mais amplos. É óbvio que essa é a doutrina dos sistemas públicos, uma teoria que nem sempre, ou quase nunca, consegue ir completamente à prática. De qualquer modo, tomando-se um referencial ético, ou até mesmo médico-sanitário, tem pequena sustentação argumentativa qualquer política em saúde que utilize somente, ou mesmo principalmente, critérios de renda para definir acesso, ainda que esta seja a realidade dominante e legal em todos os países que ainda não adotaram leis como a do SUS.

A experiência histórica tem demonstrado que há políticas e programas com efeitos mais imediatos e marcantes na distribuição de renda do que os sistemas públicos de proteção social. Assim, a valorização e defesa do valor de remuneração para o trabalho, a geração de emprego e de postos de trabalho, salário desemprego, aposentadoria, bolsas a setores carentes, reforma agrária etc. têm impacto direto na elimina- ção da miséria. As políticas públicas de saúde, segurança, habitação e de educação não poderiam ter como principal critério avaliativo seu impacto sobre a distribuição de renda, já que perseguem outros objetivos de interesse coletivo além desse.

Inúmeros estudiosos brasileiros não se enquadraram nesse reducionismo ideológico e trataram de avaliar o SUS segundo uma concepção mais ampla de eqüidade. Vianna, Fausto e colaboradores realizaram extensas avaliações tomando eqüidade como justiça quanto à alocação de recursos, à oferta e utilização de serviços conforme municípios e regiões do país. Para o período estudado encontraram que houve melhoria na distribuição de recursos e na oferta e utilização de serviços, ainda que em padrões inferiores aos recomendados pelos organismos internacionais. Encontraram também diferenças no desempenho conforme se tratassem de municípios pequenos, médios e grandes. Houve um crescimento importante do acesso ao atendimento básico em cidades com Gestão Plena do Sistema, em quatro anos saltou-se de o,28 a 1,4 consulta médica/habitante/ano. Nota-se, contudo, que esse crescimento ocorreu principalmente em função das cidades pequenas e médias, havendo expansão muito discreta nos grandes centros urbanos. Esses autores também chamam atenção para o importante fato de que a Organização Mundial de Saúde (OMS) e a Organização Pan-Americana de Saúde (OPAS) contribuíram para a valorização do conceito de eqüidade segundo uma abrangência maior do que a defendida pela contra-reforma neoliberal. Particularmente graças à estratégia denominada "Saúde para todos no ano 200o", houve uma ligação do conceito de eqüidade ao de necessidade de saúde, e não somente ao de pobreza, chegando-se a explicitar que o acesso a serviços de saúde e à proteção sanitária deveria dar-se com independência de raça, gênero, condições sociais, econômicas e culturais (Viana, Fausto et als. ; 2003).

Travassos ampliou ainda mais o enfoque com que se pretendia avaliar a eqüidade quando formulou a tese de que não se deveria avaliá-la somente com relação ao acesso, utilização de serviços e alocação de recursos, mas também considerando as desigualdades das condições de vida, que exporiam as pessoas de maneira diferente a fatores determinantes na produção de saúde e doenças (Travassos; 1997). Organismos do próprio SUS vêm desenvolvendo esforços sistemáti- 
cos para incluir indicadores de eqüidade entre os resultados levantados para orientar a gestão e a elaboração de políticas. Em 2002 foi publicado um estudo exploratório que procurou identificar desigualdades nos riscos de adoecer e morrer, bem como na atenção à saúde (Duarte et al; 2002). O enfoque ainda é de macro-região geográfica e encontraram-se disparidades importantes, com quadro desfavorável para as regiões nordeste e norte. No entanto, seria importante procederem estudos com essa metodologia considerando-se disparidades meso-regionais e mesmo aquelas internas ao próprio território de cada cidade brasileira. O Ministério da Saúde tem divulgado balanços sobre situação de saúde, demonstrando resultados positivos no controle da mortalidade infantil, ainda que já se demonstrasse uma tendência à queda antes da instalação do SUS; houve também melhora na esperança de vida dos brasileiros e no controle e erradicação de epidemias e endemias (Brasil - c; 2004). Estudos indicam a persistência de desigualdades e a emergência de disparidades antes encobertas ou inexistentes. 0 controle da epidemia de AIDS tem sido mais eficaz entre a população branca do que entre os negros; o mesmo ocorre quando o critério é gênero: a epidemia tem uma taxa de crescimento menor entre homens do que entre mulheres (IBGE; 2005). Há ainda heterogeneidade na utilização do SUS, visto que dados recentes indicam que, quanto maior a escolaridade, menor a utilização do SUS. Os serviços básicos, em franca expansão nos últimos 15 anos, bem como os de média complexidade, são mais procurados pela população de baixa renda. Já os serviços de alta complexidade têm sido utilizados por extratos sociais diversificados, em uma proporção semelhante àquela encontrada na população em geral (IPEA; 2005).

Valeria lembrar que o tema da eqüidade em saúde está também ligado à qualidade dos serviços, ou seja, à sua eficácia, à sua capacidade de resolver problemas de saúde. Ainda que haja ocorrido ampliação do acesso em atenção básica, boa parte dessa expansão vem ocorrendo graças a máquinas de produzir consulta médica e exames de laboratório sem grande preocupação com eficácia da atenção - como acontece freqüentemente com os denominados Pronto-atendimentos -, essa invenção do populismo brasileiro para ampliar, de maneira demagógica, o acesso de populações pobres dos grandes centros urbanos. A análise do modelo de atenção e de seus resultados, portanto, faz parte da discussão sobre eqüidade. Em Saúde Mental, por exemplo, haveria sentido ampliar acesso de pessoas portadoras de distúrbios mentais graves somente à internação hospitalar sem a garantia de uma rede de serviços alternativos, como os Centros de Apoio Psicossocial (CAPS), residências terapêuticas etc.?

Como analisou Lucchesi (2003), boa parte da ineficácia e iniqüidade do SUS advém de problemas da insuficiência de financiamento e do padrão inadequado de gestão. A capacidade de governo e a eficácia do controle social sobre o sistema não são homogêneas no Brasil, criando-se uma situação paradoxal em que cidades com mais recursos, por atraso político e baixa capacidade de governo, têm indicadores piores do que outras situadas em regiões com menor desenvolvimento econômico. Além disso, há o crime, desgoverno, utilização de serviços de saúde com fins eleitorais, priorização da lógica privada sobre o interesse sanitário e corrupção, hábitos tão freqüentes na gestão do estado brasileiro!

Enfim, de qualquer modo, procedendo-se a uma revisão de estudos realizados durante os últimos dez anos, não se encontram evidências suficientes que apóiem a necessidade de um contra-reforma no SUS. Não há evidências suficientes que deponham contra as diretrizes da universalidade, da integralidade, da gestão participativa, da hierarquização e da gestão descentralizada do sistema. O que há é o esgrimir político e cultural de valores e projetos distintos. O que há são evidências de que o SUS é uma reforma incompleta. Falta avançar no amadurecimento da sociedade civil - seria como se a legislação do SUS fosse mais generosa do que o Brasil real; em conseqüência, percebe-se dificuldade em garantir seu aperfeiçoamento e funcionamento regular. Faltam ações sistemáticas que dêem desdobramento conseqüente ao modelo de atenção decorrente da escolha por um sistema público de saúde. O SUS é herdeiro da tradição originária no relatório Dawson, texto fundador de um modelo de gestão e de atenção para as políticas públicas de saúde. Aprofundar essa reforma sanitária poderia transformar em realidade a potência ainda não desabrochada do sistema. A reforma da reforma do SUS não deveria, portanto, atentar contra suas diretrizes fundamentais, mas assegurar continuidade à lenta e difícil transição iniciada nos anos 1980. Transição de um 
modelo e de um paradigma, centrados na biomedicina e no mercado, para um outro que estenda a atenção primária de qualidade a pelo menos $80 \%$ dos brasileiros, e que organize de fato um sistema regionalizado e hierarquizado capaz de racionalizar o acesso aos serviços hospitalares e especializados. E, sobretudo, que dê prosseguimento à reforma democrática do estado que tem sido o SUS, ampliando as possibilidades de co-gestão do sistema, e que assegure fontes de financiamento suficientes e estáveis.

Resta a pergunta: O SUS estaria produzindo eqüidade? A resposta mais correta é sim e não. Sim, quando amplia o acesso de milhões à atenção básica, amplia a cobertura vacinal, aumenta a proporção de brasileiros com possibilidade de tratar-se de AIDS, câncer, saúde mental etc.. Não, quando ainda persistem diferenças de acesso em função de critérios que não os sanitários, mas em razão de obstáculos decorrentes da política e da gestão do sistema.

A busca da eqüidade deverá ser permanente, considerando sempre as múltiplas dimensões do conceito. Um trabalho permanente de engenharia política, da arte da gestão e de sabedoria sanitária. Um projeto somente sustentável em um contexto sócio-histórico em que a vida das pessoas seja o bem mais valioso, entre todos. Um projeto a ser sustentado para além das evidências concretas de cada época, um projeto enganchado na teimosia, bem humana, de que a vida pode sempre melhorar, ainda que nem sempre isso seja uma evidência palpável.

\section{Referências}

ALMEIDA, C. M. Equidade e reforma setorial na América Latina. Cadernos de Saúde Pública, Rio de Janeiro, v. 18, p. 23-26, 2002. Suplemento.

ARISTÓTELES. Ética a Nicômaco. Tradução: Antônio Caieiro. Lisboa: Quetzal, 2004. p. 285.

BOBBIO, N. Teoria geral da política: a filosofia política e as lições dos clássicos. Organização: Michelangelo Bovero. Tradução: Daniela B. Versiani. Rio de Janeiro: Campus, 2000.

BRASIL. Constituição (1988). Constituição da República Federativa do Brasil. Brasília, DF: Senado, 1988. Título VIII - Da Ordem Social, Seção II - Da Saúde artigo 196-200.
BRASIL. Ministério da Saúde. Lei federal número 8080 de 19 de setembro de 199o. Brasília, DF, 1990.

BRASIL. Ministério da Saúde. Secretaria de Vigilância em Saúde. Saúde Brasil 2004: uma análise da situação de saúde. Brasília, DF, 2004.

CAMPOS, G. W. S. Um método para análise e co-gestão de coletivos. São Paulo: Hucitec, 2000.

COMTE-SPONVILlE, A. Dicionário filosófico. Tradução: Eduardo Grandão. São Paulo: Martins Fontes, 2003.

DELEUZE, G.; GUATTARI, F. O que é a filosofia? . Tradução: Bento Prado Júnior e Alberto Alonso Munhoz. Rio de Janeiro: Editora 34, 1992.

DRACHLER, M. L.; CÔRTES, S. M. V.; CASTRO, J. D.; LEITE, J. C. C. Proposta de metodologia para selecionar indicadores de desigualdade em saúde visando definir prioridades de políticas no Brasil. Ciência \& Saúde Coletiva, Rio de Janeiro, v. 8, n. 2, p. 461-479, 2003.

DUARTE, E. C. et al. Epidemiologia das desigualdades no Brasil: um estudo exploratório. Brasília: Organização Pan-Americana de Saúde, 2002.

ESCOREL, S. Os dilemas da equidade em saúde: aspectos conceituais. Brasília, DF: OPAS, 2001. Disponível em: www.opas.org.br/serviços/arquivos. Acesso em:10 jan, 2006.

IBGE. Brasil em números/Brazil in figures. Brasília: Centro de Documentação e Disseminação de Informação, 2005. v. 13.

IPEA. Acompanhamento e análise de políticas sociais: saúde. Boletim de Acompanhamento, Brasília, p. 49, ago. 2005. Disponível em: www.ipea.gov.br/pub/bps. Acesso em: 10 jan, 2006.

LUCCHESE, P. T. R. Equidade na gestão descentralizada do SUS: desafios para redução de desigualdades. Ciência e Saúde Coletiva, Rio de Janeiro, v. 8, n. 2, p. 439-448, 2003.

MARX, K.; ENGELS, F. Manifesto comunista. 6.ed. São Paulo: Paz e Terra, 2000.

PELLEGRINI FILHO, A. Pesquisa em saúde, política de saúde e equidade na América Latina. Ciência e Saúde Coletiva, Rio de Janeiro, v. 9, n. 2, p. 339-350, 2004. 
POCHMANN, M. Proteção social na periferia do capitalismo. São Paulo em Perspectiva, São Paulo, v. 18, n. 2, p. 3-16, 2004 .

RIZZOTO, M. L. F. O Banco Mundial e as políticas de saúde no Brasil nos anos noventa: um projeto de desmonte do SUS. Tese (Doutorado em Medicina Preventiva e Social) - Faculdade de Ciências Médicas, UNICAMP, Campinas, 2001.

SIQUEIRA-BATISTA, R.; SCHRAMM, F. R. A saúde entre a iniqüidade e a justiça: contribuições de Amartya Sen. Ciência \& Saúde Coletiva, Rio de Janeiro, v. 1o, n. 1, p. 129-145, 2005.
STARFIELD, B. Improving equity in health: a research agenda. International Journal of Health Services, Westport, v. 3, n. 3, p. 545- 566, 2001.

TRAVASSOS, C. Equidade e o sistema único de saúde: uma contribuição para o debate. Cadernos de Saúde Pública, Rio de Janeiro, v. 13, n. 2, p. 325-330, 1997.

VIANNA, A. L.; FAUSTO, M. C. R.; LIMA, L. D. Política de saúde e equidade. São Paulo em Perspectiva, São Paulo, v. 17, n. 1, p. 58-68; 2003.

WHITEHEAD, M. The concepts and principles of equity in health. International Journal of Health Services, Westport, v. 22, p. 429-445, 1992. 